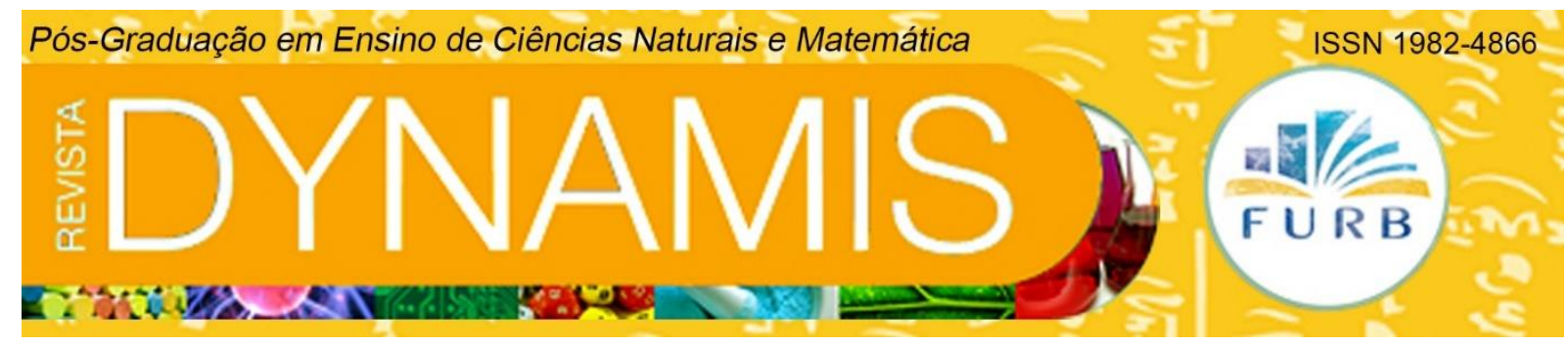

\title{
UMA ANÁLISE PARA A TRANSPOSIÇÃO DIDÁTICA DA CINÉTICA QUÍMICA
}

An analysis for the didactic transposition of chemical kinetic

Priscila do Nascimento Silva

Mestranda no Programa de Pós-Graduação em Ensino das Ciências (PPGEC)

Universidade Federal Rural de Pernambuco

e-mail: priscilnascimento@yahoo.com.br

José Euzebio Simões Neto

Doutor em Ensino das Ciências

Docente do Departamento de Química (DQ)

Universidade Federal Rural de Pernambuco

Docente do Programa de Pós-Graduação em Educação em Ciências e Matemática (PPGECM)

Universidade Federal de Pernambuco

e-mail: euzebiosimoes@gmail.com

Flávia Cristiane Vieira da Silva

Doutora em Ensino das Ciências

Docente da Unidade Acadêmica de Serra Talhada (UAST)

Universidade Federal Rural de Pernambuco

e-mail: flavia.cristianevs@gmail.com 


\title{
Resumo
}

Podemos entender o processo de transposição didática como o conjunto de modificações as quais saber é submetido, da esfera acadêmica (saber científico) para o âmbito escolar, em duas etapas: externa (produz o saber a ser ensinado) e interna (produz o saber ensinado). Neste trabalho, analisamos a transposição didática do conteúdo cinética química, incialmente com foco na fase externa da transposição, observando as modificações até o estabelecimento do saber escolar. Em um segundo momento, procuramos identificar a partir de uma entrevista com três professores do Ensino Médio evidências do trabalho intramuros da sala de aula, com foco na etapa interna da transposição. Identificamos um processo de transposição rico em supressões e com a ocorrência de acréscimos e criações didáticas. Ainda, foi possível observar que a relação do professor ao saber determina o tempo de ensino do conteúdo, a repersonalização e recontextualização do saber e as estratégias didáticas utilizadas em sua prática.

Palavras-chave: Transposição Didática. Cinética Química. Ensino de Química.

\begin{abstract}
We can understand the process of didactic transposition as the set of modifications that know is submitted from the academic sphere (scientific knowledge) to the school environment, in two stages: external (produces the knowledge to be taught) and internal (produces the knowledge taught). In this work, we analyze the didactic transposition of the chemical kinetic content, initially focusing on the external phase of the transposition, observing the modifications until the production of the school knowledge. In a second moment, we try to identify from an interview with three high school teachers evidences of the intramural work of the classroom, focusing on the internal stage of the transposition. We identified a process of transposition rich in suppressions and with the occurrence of additions and didactic creations. Still, it was possible to observe that the relation of the teacher to the knowledge determines the time of teaching of the content, the repersonalization and recontextualization of the knowledge and the didactic strategies used in their practices.
\end{abstract}

Keyworks: Didactic Tranposition; Chemical Kinect; Chemistry teaching. 


\section{INTRODUÇÃO}

Na sala de aula, local em que se estabelece uma relação didática, quando um determinado saber deve ser ensinado pelo professor e aprendido pelos alunos, emergem os fenômenos didáticos. Nessas situações, se relacionam a tríade professor-aluno-saber, em um meio específico, ou millieu (ALMOULOUD, 2011), constituindo o que Brousseau (1986) definiu como situação didática, que pode ser expressa no triângulo das situações didáticas, ilustrado na figura 1.

\section{Figura 1- Triângulo das Situações Didáticas}

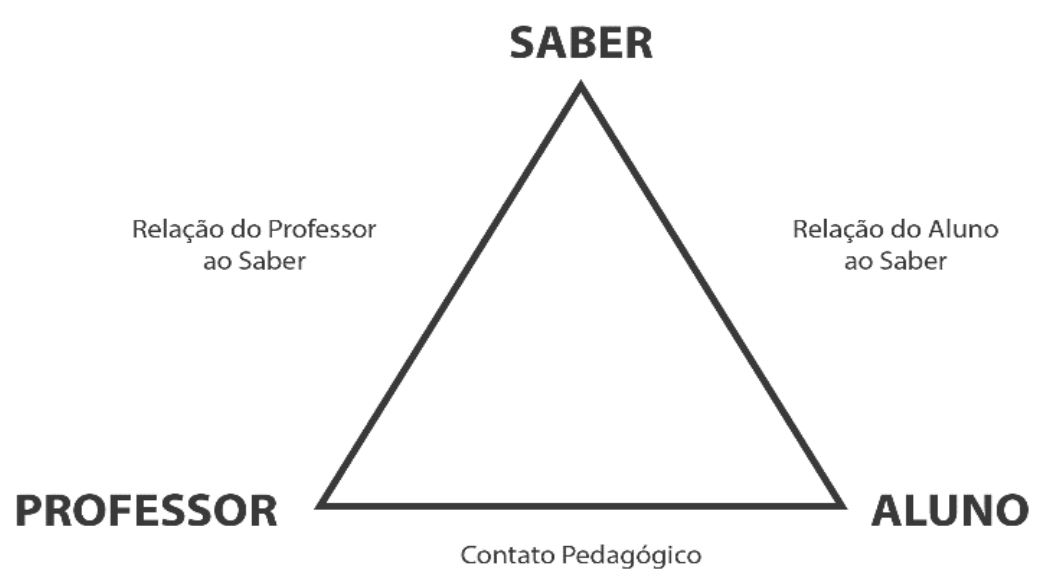

Fonte: Brousseau (1986)

Pensar sobre essa relação ternária implica em colocar em cena uma série de conceitos articulados de forma complexa, para que seja possível compreender a maneira dinâmica e encadeada como tais relações se instituem (BRITO MENEZES, 2006). No entanto, tal saber, denominado científico e constituinte da situação didática, não é o mesmo que é construído e consumido nas academias e centros de pesquisa. Até chegar à escola, o saber científico deve passar por uma série de modificações, que envolvem sistematização e didatização. Chevallard (1991) denomina esse processo de Transposição Didática (MENEZES, 2006; SILVA; SILVA; SIMÕES NETO, 2015).

O estudo desse fenômeno possibilita analisar a trajetória que se cumpre desde a produção do saber científico até o momento em que este se transforma em objeto de ensino. É evidente que a transposição didática precisa ser adequada para cada nível, para que, como afirma Chevallard, possa se tornar compreensível para o estudante (FRANZOLIN; TOLETINONETO; BIZZO, 2014). Aprender a compreender e realizar essas transformações do saber, transformando-o em um saber apropriado para a aprendizagem do aluno, torna-se um desafio para os professores.

De fato, selecionar, organizar e adequar o conhecimento a ser ensinado estão entre as tarefas mais importantes do professor. Nos cursos de licenciatura, os conceitos científicos são trabalhados com relativo grau de aprofundamento e é comum encontrarmos estudantes concluintes da graduação afirmando certo receio de ir para a sala de aula, por não se sentirem preparados com relação à gestão dos conceitos aprendidos em situações de ensino e aprendizagem. 
Existe, pois, uma diferença de natureza e intencionalidade entre o saber científico e o saber escolar: no contexto científico, o pesquisador, quando da criação de uma lei ou teoria, "despersonaliza, descontextualiza e destemporiza o máximo possível seus resultados" (BROUSSEAU, 1999, p. 37), sendo atribuição do professor realizar o papel inverso, ou seja, ele tem a função de recontextualizar e repersonalizar esse saber.

É importante ressaltar alguns fatores importantes, como a gestão do tempo: o tempo de ensino, que é previamente estabelecido pelo calendário acadêmico ou escolar, o tempo de aprendizagem, que é o tempo que o saber fica efetivamente em cena no jogo didático (CHEVALLARD, 1991) e o tempo do professor, relacionado com a dilatação ou restrição do tempo que cada saber fica em cena (SANTOS, 1997). A gestão do tempo é fundamental para o sucesso das situações didáticas.

$\mathrm{Na}$ abordagem do conteúdo de cinética química, as atividades didáticas muitas vezes são baseadas em aulas expositivas, como na maior parte dos conteúdos da química escolar, que não consideram os conhecimentos prévios dos estudantes e as aplicações cotidianas, o que torna o ensino deste tópico abstrato e pouco motivador (LIMA et al., 2000; MARTORANO, 2000). A compreensão da velocidade das reações químicas envolve a interpretação de dados experimentais e a compreensão do caráter dinâmico das partículas. Contudo, é um conceito extremamente importante e que apresenta aplicações no cotidiano, tais como processos industriais e reações que ocorrem no organismo dos seres vivos (MARTORANO, 2007).

Diante do exposto, apresentamos o objetivo dessa pesquisa, que buscou analisar o processo de transposição didática do conteúdo cinética química, observando de que forma esses conceitos são abordados nos livros didáticos e intramuros da sala de aula.

\section{A TRANSPOSIÇÃO DIDÁTICA DE YVES CHEVALLARD}

A Transposição Didática foi formulada originalmente pelo sociólogo Michel Verret, em 1975. Porém, em 1980, o educador matemático Yves Chevallard retoma essa ideia e a insere num contexto mais específico, fazendo dela uma noção importante nos estudos da Educação Matemática. No entanto, apesar de ter sua origem no campo da Didática da Matemática, essa noção pode ser aplicável ao ensino de ciências naturais, como a Química, com o aval do próprio Chevallard (NEVES; BARROS, 2011).

Assim, a Transposição Didática é um instrumento pelo qual analisamos o movimento do saber sábio (ou saber científico), aquele que os cientistas descobrem para o saber a ensinar, aquele que está nos livros didáticos e, por este, ao saber ensinado, aquele que é efetivado em sala de aula (BATISTA FILHO et al., 2012). Em outras palavras, ela pode ser entendida como a transformação do saber científico ao saber ensinado. Desta forma, podemos entender três diferentes manifestações do saber, com objetivos e linguagens distintas: saber científico, saber a ser ensinado e saber ensinado, que serão discutidos com mais detalhes na sequência.

Podemos compreender que o saber científico é aquele produzido no bojo da pesquisa, dentro de uma comunidade acadêmica, por cientistas. Inicialmente, tem uma linguagem pessoal e é altamente codificado, um labirinto de reflexões (MELZER, 2012). O processo de produção do saber científico é explicado por Brousseau (1986), que entende ser papel do pesquisador despersonalizar, descontextualizar e destemporizar seus resultados. Observamos uma omissão d o contex to no qual o cientista esteve imerso durante o desenvolvimento da sua pesquisa, sendo a comunicação dos resultados limpa, depurada e impessoal, numa direção que Chassot (1993) entende como assepsia da ciência.

ISSN 1982-4866. Revista Dynamis. FURB, Blumenau, v. 22, n. 2, p. 3-17, 2016 
O saber a ser ensinado, reconhecido nos chamados textos do saber, de acordo com Chevallard (1991), é oriundo do saber científico, totalmente reorganizado e apresentado de forma mais simplificada, com o objetivo de ser um saber de mais fácil compreensão, ou seja, mais adequado para a aprendizagem, constituindo-se em objetos didáticos. Pinho-Alves (2000) faz uma distinção entre os personagens definidores do saber a ensinar e saber sábio:

\begin{abstract}
Os personagens definidores do saber a ensinar não pertencem a um só grupo, como na esfera do saber sábio. Nesta última, o grupo é constituído de intelectuais e cientistas, sejam jovens e idosos, com ou sem conflitos teóricos, vinculados a esta ou aquela escola de pensamento, todavia todos são pertencentes ao mesmo nicho epistemológico em que ocorre a produção do saber (PINHO-ALVES, 2000, p. 225)
\end{abstract}

Já o saber ensinado, de acordo com Astolfi e colaboradores (1997) e também Chevallard (1991), é aquele comunicado em sala de aula, dentro do sistema didático, caracterizado pela figura do professor, que prepara sua aula e interpreta o saber a ensinar, elaborando um novo texto do saber, que é construído a partir do texto do saber, e é impregnado das percepções e conjecturas do professor, sendo então determinante para a sua construção a relação do professor ao saber.

Chevallard (1991) assume que o processo de transposição ocorre em duas etapas, a saber: uma primeira etapa, strictu sensu, que ocorre fora da escola, por isso chamada de transposição didática externa (TDE), que transforma o saber científico em saber a ser ensinado; E uma segunda etapa, lato sensu, que transforma o saber a ser ensinado em saber ensinado, intramuros da sala de aula e por isso chamada de transposição didática interna (TDI). O processo na íntegra é apresentado na figura 2:

\title{
Figura 2- O processo de Transposição Didática segundo Chevallard
}

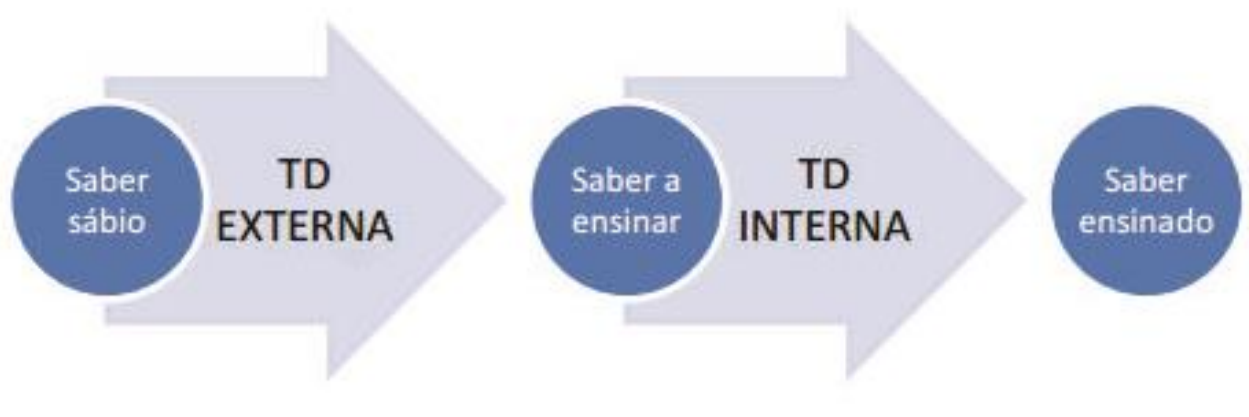

Fonte: Melzer (2012)

A Transposição Didática Externa é realizada por uma instituição dita invisível, denominada por Chevallard (1991) como noosfera, termo que se origina na antropologia e representa a esfera relacionada ao conhecimento. Tal instituição é composta por didatas, professores, pedagogos, técnicos educacionais e membros do governo, que gerenciam o ensino (MENEZES, 2006) e são responsáveis por estabelecer o que deve ser ensinado nas escolas. Nesse processo, é fundamental o papel da vigilância epistemológica, que surge quando professores e/ou pesquisadores questionam o saber a ser ensinado em sua natureza (CHEVALLARD, 1991). Tal instituição tenta impedir a criação de dogmas, o engessamento 
do conhecimento, as deformações e criações didáticas de efeitos indesejáveis, garantindo uma qualidade na preservação do conceito relacionado ao saber durante o processo.

Já na Transposição Didática Interna, o professor assume um papel central, pois o saber que entra em cena no jogo didático se manifesta a partir do novo texto do saber, que é impregnado pela relação do professor ao saber (SANTOS, 1997). De acordo com Menezes (2006) na relação didática, o professor nem sempre (ou quase nunca) terá acesso ao saber original, mas à sua adaptação/transformação, através dos manuais de ensino e livros didáticos, e ainda é o responsável por mais uma etapa nessa adaptação, que acontecerá no cerne da relação didática. Nesse processo de sucessivas adaptações poderão surgir acréscimos, supressões, deformações, criações didáticas, entre outros, que têm objetivo didático, ou seja, servem como artifício para favorecer a apropriação, pelos alunos, do conhecimento em questão.

Assim, intramuros da sala de aula, cabe ao professor transformar o saber a ser ensinado em saber ensinado, mediante processos que direcionem, entre outras ações, uma repersonalização e recontextualização do saber. Esses processos, de repersonalização e recontextualização, podem ser entendidos como a ação do professor em relacionar o saber a ser ensinado, que é livre e isento de contextos específicos, com a realidade em que está inserido e com suas próprias percepções, com base na sua relação ao saber (SILVA; SILVA; SIMÕES NETO, 2015).

Bessa de Menezes, Brito Menezes e Ramos (2004, p. 7) apresentam uma síntese do processo de transposição didática bastante interessante:

\footnotetext{
Podemos concluir que o fenômeno da transposição didática ocorre, a princípio, em duas etapas: uma externa a sala de aula, onde o saber sofre influências sociais para a sua escolha de acordo com o momento histórico; e outro que ocorre no interior da sala de aula, que tem no professor, através de sua relação com o saber em jogo, seu principal ator.
}

Durante o processo de transposição didática surgem modificações significativas na estrutura do saber, tais como: deformações (quando o saber permanece, mas tem sua estrutura modificada durante a transposição), supressões (quando um saber é suprimido durante a transposição), acréscimos (quando informações são adicionadas para, por exemplo, contextualizar o saber) e criações didáticas (trata-se de um tipo específico de acréscimo, associado ao compromisso de ensino e aprendizagem, buscando modelos e exemplos para melhor explicar ou sistematizar um conteúdo). Essas ações são importantes para que o saber em questão possa ser ensinado e aprendido nas escolas. Todavia, é essencial uma postura cuidadosa na gestão dessas modificações, que podem ser prejudiciais se atuam por desfigurar o saber original, criando obstáculos à aprendizagem.

\section{REFLETINDO SOBRE A APRENDIZAGEM DA CINÉTICA QUÍMICA}

O desenvolvimento da Ciência Química, como campo de interesse científico e tecnológico, trouxe benefícios para a sociedade e melhoria na qualidade de vida das pessoas. Santos e Schnetzler (2003, p. 48-49) relatam "[...] que a melhoria na qualidade de vida no século atual é também atribuída ao desenvolvimento da química, pois os materiais que aumentam o nosso conforto e preservam a nossa saúde são produtos químicos".

ISSN 1982-4866. Revista Dynamis. FURB, Blumenau, v. 22, n. 2, p. 3-17, 2016 
Nesse contexto, a cinética química como um campo da Química, é importante para contribuir decisivamente no processo de conservação dos alimentos, buscando novas maneiras de armazenamento e aprimorando os meios já existentes, buscando maior eficiência, sem causar prejuízo na sua constituição e propriedade dos alimentos, garantindo, além da conservação, a manutenção de sabores, aroma e textura.

No entanto, quando consideramos especificamente o ensino de cinética química, constatamos que as atividades didáticas, muitas vezes, são baseadas basicamente em aulas expositivas, que não levam em consideração os conhecimentos prévios dos alunos e as aplicações da Cinética Química em contextos cotidianos. Essa opção por uma pedagogia tradicional em essência torna o ensino deste tópico desmotivador e o discurso do professor quase sempre tomado como dogmático, status corroborado pela abordagem dos livros didáticos.

A falta de contextualização do saber químico pode ser responsável pelo alto nível de rejeição do estudo desta ciência pelos alunos, dificultando os processos de ensino e aprendizagem. Trabalhar de forma contextualizada, segundo Chassot (1993), não impede que o aluno resolva as questões clássicas de química, principalmente se elas forem elaboradas buscando avaliar além da evocação de dados e fatos, mas também a capacidade de trabalhar o conhecimento em diferentes contextos.

Segundo Martorano, Carmo e Marcondes (2014), o conhecimento do tema cinética química é importante, pois possibilita ao aluno o entendimento de diversos processos que estão presentes em seu cotidiano como, por exemplo, a conservação de alimentos e o uso de catalisadores nos veículos e em indústrias. Contudo, percebemos que somente essas justificativas para a apresentação da Cinética Química como conteúdo escolar não têm sido suficientes para que os professores modifiquem suas práticas na abordagem da velocidade das reações. Desta forma, justificamos a escolha, nesse estudo, pelo conteúdo de cinética química para a análise da transposição didática.

\section{METODOLOGIA}

Essa pesquisa foi dividida em duas etapas, cada uma relacionada com um movimento de Transposição Didática (externa e interna). Na primeira etapa, buscamos analisar o processo de Transposição Didática Externa (TDE) para o conteúdo Cinética Química. Assim, selecionamos cinco livros do Ensino Médio, como exemplos de manifestação do texto do saber, portanto produtos da transposição didática externa, com objetivo de realizar uma análise comparativa com o livro do Ensino Superior, que chamaremos de livro de referência (LR) e tratado como manifestação do saber científico.

Esta opção se sustenta a partir de uma aproximação válida: entendemos que os livros didáticos do Ensino Superior são produtos de transposição didática, ou seja, também textos do saber: são didáticos e portadores de intencionalidade para ensino. No entanto, como ocorrem menos modificações durante os movimentos de transposição didática, são tomados como manifestação do saber científico (SILVA et al., 2013; SILVA; SILVA; SIMÕES NETO, 2014; SILVA; SILVA; SIMÕES NETO, 2015). Os livros selecionados foram divididos em dois grupos, sendo dois anteriores e três posteriores a proposta do novo Exame Nacional do Ensino Médio (ENEM), que busca valorizar mais contexto e problematizações. As obras selecionadas são apresentadas no quadro1:

ISSN 1982-4866. Revista Dynamis. FURB, Blumenau, v. 22, n. 2, p. 3-17, 2016 
Quadro 1 - Livros Didáticos Analisados

\begin{tabular}{|c|c|c|c|}
\hline $\begin{array}{l}\text { Livro } \\
\text { Didático }\end{array}$ & Representação & Ano de Publicação & $\begin{array}{l}\text { Definição da } \\
\text { Proposta }\end{array}$ \\
\hline Livro Didático 1 & LD1 & 1990 & \multirow{2}{*}{$\begin{array}{c}\text { Tradicional } \\
\text { (Anterior ao NOVO } \\
\text { ENEM) }\end{array}$} \\
\hline Livro Didático 2 & LD2 & 2004 & \\
\hline Livro Didático 3 & LD3 & 2009 & \multirow{3}{*}{$\begin{array}{c}\text { Contextualizado e } \\
\text { Problematizado } \\
\text { (Posterior ao NOVO } \\
\text { ENEM) }\end{array}$} \\
\hline Livro Didático 4 & LD4 & 2011 & \\
\hline Livro Didático 5 & LD5 & 2013 & \\
\hline
\end{tabular}

Fonte: Elaborado pelos autores

Buscamos identificar modificações no saber, tais como: acréscimos (informações adicionais contidas no texto do saber e não estão presentes no saber científico), supressões (conceitos e ideias removidos durante o processo), criações didáticas (estratégias e metodologias que abordam de maneira diferenciada o saber científico para o contexto escolar) e deformações (quando o saber a ser ensinado é modificado de maneira que se afasta do saber original).

Para a análise, elencamos alguns critérios a priori, baseado em importantes ideias associadas ao conteúdo de cinética química, discriminados no quadro 2 :

Quadro 2- Critérios de análise a priori para a transposição didática externa (TDE)

\begin{tabular}{|c|l|}
\hline Tópico do conceito de cinética química & \multicolumn{1}{|c|}{ Critérios para observações } \\
\hline Lei das velocidades & $\begin{array}{l}\text { Definição, lei de Guldberg-Waage, ordem } \\
\text { de Reação e classificação das reações em } \\
\text { elementares e não-elementares. }\end{array}$ \\
\hline $\begin{array}{c}\text { Fatores que influenciam a velocidade das } \\
\text { reações químicas. }\end{array}$ & $\begin{array}{l}\text { Influência da temperatura, concentração, } \\
\text { superfície de contato e catalisadores. }\end{array}$ \\
\hline Teoria das colisões & $\begin{array}{l}\text { Choques entre reagentes, energia de } \\
\text { ativação e complexo ativado. }\end{array}$ \\
\hline
\end{tabular}

Fonte: Elaborado pelos autores

Na segunda etapa buscamos analisar a transposição didática interna, a partir de entrevista semiestruturada com professores de química que atuam no Ensino Médio. O quadro 3 apresenta o perfil destes professores:

Quadro 3- Perfil dos professores entrevistados

\begin{tabular}{|c|c|l|}
\hline Professor (a) & Experiência Docente & \multicolumn{1}{|c|}{ Formação Acadêmica } \\
\hline P1 & 5 anos & Graduando em Licenciatura em Química \\
\hline P2 & 4 anos & $\begin{array}{l}\text { Licenciado em Química e Mestrado em } \\
\text { Ensino de Ciências }\end{array}$ \\
\hline P3 & 23 anos & $\begin{array}{l}\text { Licenciado em Química com Mestrado e } \\
\text { Doutorado em Energia Nuclear }\end{array}$ \\
\hline
\end{tabular}

ISSN 1982-4866. Revista Dynamis. FURB, Blumenau, v. 22, n. 2, p. 3-17, 2016 
Fonte: Elaborado pelos autores

Para a entrevista, desenvolvemos cinco questões relacionadas a gestão do conteúdo cinética química para identificar indícios do trabalho do professor intramuros da sala de aula. No quadro 4 elencamos as perguntas e seus respectivos objetivos.

\section{Quadro 4- Perguntas da entrevista e seus objetivos}

\begin{tabular}{|l|l|}
\hline \multicolumn{1}{|c|}{ Perguntas } & \multicolumn{1}{|c|}{ Objetivo } \\
\hline $\begin{array}{l}\text { Quanto tempo, ou quantas aulas você } \\
\text { dispõe para abordagem do conteúdo de } \\
\text { cinética química? }\end{array}$ & $\begin{array}{l}\text { Levantar informações acerca do tempo em } \\
\text { que o saber fica em cena no jogo didático, } \\
\text { baseado na dimensão temporal do trabalho } \\
\text { docente intramuros sala de aula }\end{array}$ \\
\hline $\begin{array}{l}\text { Como você organiza a sequência de aulas } \\
\text { sobre cinética química? }\end{array}$ & $\begin{array}{l}\text { Observar a escolha e sistematização do } \\
\text { conteúdo pelo professor }\end{array}$ \\
\hline $\begin{array}{l}\text { Quais mudanças você pode elencar entre o } \\
\text { conhecimento científico e o conhecimento } \\
\text { escolar no conteúdo de cinética química? }\end{array}$ & $\begin{array}{l}\text { Identificar quais das modificações são } \\
\text { reconhecidas e consideradas pelo professor } \\
\text { em sua prática docente. }\end{array}$ \\
\hline $\begin{array}{l}\text { O que você considera mais importante } \\
\text { neste conteúdo que é ensinado ao aluno? }\end{array}$ & $\begin{array}{l}\text { Relacionar a dimensão temporal com a } \\
\text { escolha dos conteúdos, na transposição } \\
\text { didática interna (TDI). }\end{array}$ \\
\hline $\begin{array}{l}\text { Como você encara os processos de } \\
\text { recontextualização e repersonalização dos } \\
\text { saberes no conteúdo de cinética química? }\end{array}$ & $\begin{array}{l}\text { Identificar as opções e ações dos } \\
\text { professores quanto aos processos de } \\
\text { recontextualização e repersonalização do } \\
\text { saber intramuros da sala de aula. }\end{array}$ \\
\hline
\end{tabular}

Fonte: Elaborado pelos autores

A partir das respostas, elencamos elementos que dão indícios da forma em que o saber em questão é gerido intramuros da sala de aula, o que fornece direcionamentos sobre o trabalho de transposição didática interna realizada pelo professor.

\section{RESULTADOS E DISCUSSÃO}

Apresentaremos os resultados divididos em duas partes, a saber: Análise da transposição didática externa do Conteúdo de Cinética Química e a Entrevista Semiestruturada com Professores de Química, na qual buscamos relacionar aos movimentos associados ao processo de transposição didática interna, a partir da fala dos professores sobre o seu trabalho intramuros da sala de aula.

\subsection{ANÁLISE DA TRANSPOSIÇÃO DIDÁTICA EXTERNA}

Na primeira etapa buscamos observar o processo da transposição didática externa a partir da análise comparativa entre livros didáticos selecionados e o Livro de Referência.

\section{$\underline{\text { Lei das Velocidades }}$}


a) todas as obras do Ensino Médio conceituam a lei da velocidade como sendo a relação entre as concentrações dos reagentes e a velocidade de ocorrência de uma reação química. De forma diferente, o livro de referência conceitua a lei da velocidade já trazendo um exemplo de aplicação da lei em contexto científico;

b) apenas LD4 apresenta uma discussão histórica, buscando reflexão sobre a importância desta lei na época e na atualidade, evidenciando a importância de estudar cinética química. Tal contexto não é apresentado no livro de referência e consideramos como um movimento de acréscimo. Ainda, LD2 e LD3 não associam a lei da velocidade aos trabalhos de Guldberg e Waage, o que consideramos uma supressão histórica;

c) assim como é apresentado no livro de referência, LD1 e LD4 explicam que a lei da velocidade não mede a velocidade média da reação, e sim, a instantânea. Consideramos a supressão dessa informação um movimento prejudicial nos demais livros do Ensino Médio;

d) LD1 e LD5 não apresentam definição para ordem de reação, como também não apresentam a classificação das reações em elementares e não elementares, embora comentem que estas podem ocorrer em uma ou mais de uma etapa. LD5 não é apresenta a lei das velocidades em sua definição matemática, ocorrendo supressão;

e) a definição de tempo de meia vida é suprimida em todas as obras do Ensino Médio analisadas, sendo abordada apenas no tópico destinado a radioatividade.

\section{Fatores que influenciam a velocidade das reacões químicas}

a) todos os livros analisados são coerentes com os livros de referência, discutindo aspectos relacionados a concentração, temperatura, superfície de contato e catalisadores para discutir os fatores que influenciam a velocidade das reações químicas;

b) entre as obras para o Ensino Médio, apenas em LD1 as enzimas não são discutidas, o que caracteriza supressão nos demais livros analisados;

c) a classificação da catálise em homogênea e heterogênea é apresentada apenas em LD1 e LD3, abordagem que se aproxima bastante do livro de referência;

d) o livro de referência afirma que os catalisadores podem ser envenenados ou inativados, na discussão sobre inibidores ou veneno de reação. Apenas LD3 não apresenta informações sobre esse tipo de substância e seus efeitos nas reações. LD4 e LD5 colocam os inibidores como uma classe a parte dos catalisadores, o que caracteriza uma deformação.

\section{Teoria das Colisões}

a) no livro de referência são apresentadas expressões como a equação de Arrhenius (calcular a variação da constante de velocidade com a temperatura) e o cálculo das frequências de colisão entre as moléculas. Nenhuma das obras do Ensino Médio aborda 
essas expressões, o que caracterizamos como supressão, para esse caso positiva, pois parece mais interessante compreender os fenômenos, e não realizar cálculos específicos;

b) em coerência com o livro de referência, LD1 e LD4 argumentam que, para que exista reação química, deve existir quebra e formação de ligações químicas, e isso ocorre a partir de colisões efetivas. LD3 associa a teoria das colisões à classificação em reações elementares e não-elementares, considerando que colisões favoráveis direcionam a ocorrência de reação elementar, o que entendemos como um exemplo de deformação;

c) LD5 faz uso de modelos representacionais, mas, diferente das outras obras analisadas e do livro de referência, afirma que tal representação é um modelo para explicar a ocorrência das reações químicas e as colisões necessárias para a formação do produto. Essa justificativa se constitui como um acréscimo bastante relevante, pois evita que ocorram obstáculos a aprendizagem, derivados da ideia de que os choques acontecem com moléculas em específico, de maneira organizada e direta;

d) todas as obras analisadas relacionam a colisão efetiva como sendo derivada de uma orientação favorável e uma energia mínima necessária para que reação ocorra. Essa coerência evita confusões e dificuldades no ensino e aprendizagem deste saber;

e) o livro de referência apresenta a energia de ativação como a energia mínima necessária para que a reação química ocorra, a partir da formação de um estado de transição chamado de complexo ativado. A abordagem nas obras analisadas é bem coerente com o livro de referência, porém, não utilizam o termo "estado de transição" ao tratar do complexo ativado, que é definido como uma estrutura intermediária, caracterizando uma deformação.

\subsection{ANÁLISE DA TRANSPOSIÇÃO DIDÁTICA INTERNA: ENTREVISTA COM OS PROFESSORES}

Entrevistamos três professores de química, que atuam no Ensino Médio sobre o seu trabalho intramuros da sala de aula. As respostas às perguntas e as discussões foram:

\section{a) Quanto tempo, ou quantas aulas você dispõe para abordagem do conteúdo de cinética química?}

Os professores P1 e P3 trabalham o conteúdo destinando praticamente o mesmo tempo, respectivamente, dez e nove aulas. Já o professor P2 destina menor tempo para a abordagem da velocidade das reações, organizando suas aulas em torno de seis a sete momentos. Neste aspecto, destacamos que cada professor entrevistado considera a diversidade de suas salas de aula, uma vez que todos se mostraram flexíveis com o tempo do saber em cena no jogo didático.

Podemos tentar explicar o menor tempo destinado a cinética química por P2 a partir da relação ao saber: ao longo de sua atuação profissional, se dedicou mais ao ensino de química orgânica, portanto, possivelmente construiu uma relação mais forte com essa área.

\section{b) Como você organiza a sequência de aulas sobre Cinética Química?}


A preocupação com a recontextualização é evidente no trabalho dos três professores, com destaque para o professor $\mathrm{P} 3$, que trabalha um pouco diferente dos demais, em uma perspectiva que vai além do direcionamento ao ENEM.

Inicialmente, P3 localiza a cinética química no cotidiano dos estudantes, falando da velocidade dos fenômenos químicos como a formação do petróleo e a oxidação das frutas. Depois, trata dos fatores que influenciam a velocidade de uma reação através de um experimento com comprimido efervescente inteiro, picado e pulverizado, colocado em recipientes com água em diferentes temperaturas. Destacamos a abordagem da teoria das colisões, na qual P3 retoma alguns conteúdos de termodinâmica química, utilizando o gráfico entre energia e caminho da reação. Ainda, afirma que trabalha com o tempo de meia vida das reações químicas. Tal conceito não é encontrado em nenhuma das obras analisadas (supressão), mas é discutido pelo professor em sala de aula.

O professor P1 relata de maneira mais superficial sua sequência de aulas, mesmo assim, é possível observar uma preocupação maior em dar ênfase à aplicabilidade desses conceitos no cotidiano dos alunos, na realização de experimentos e resolução de questões do ENEM. Por fim, o professor P2 introduz os conceitos básicos de cinética e os fatores que influenciam a velocidade das reações nas duas primeiras aulas. Em seguida, trabalha os cálculos químicos relacionados à velocidade das reações, teoria das colisões e ação de catalisadores. Então, para finalizar, dedica duas aulas para a realização de alguns experimentos em sala e exercícios.

\section{c) Quais mudanças você pode elencar entre o conhecimento científico e o conhecimento escolar no conteúdo de cinética química?}

Existe uma convergência de opiniões entre os três professores em relação a simplificação das abordagens matemáticas, que muitas vezes exigem uma matemática mais elaborada, algumas vezes envolvendo cálculo diferencial e integral. Os professores P2 e P3 argumentam sobre essas simplificações, destacando a equação de Arrhenius, meia vida e análises gráficas. Ainda, o professor P1 elenca limitações quanto a conhecimentos conceituais e procedimentais, além de não ter a sua disposição espaços físicos e equipamentos para realização de atividades experimentais envolvendo cinética química, na escola do Ensino Médio.

Os professores entrevistados não comentaram sobre as modificações ocorridas na estrutura do saber relacionado a teoria das colisões.

\section{d) O que você considera mais importante neste conteúdo que é ensinado ao aluno?}

Os professores P1 e P3 concordam que o mais importante é fazer com que o aluno possa relacionar os conhecimentos de cinética química com o cotidiano e com outras ciências, como biologia e física, numa perspectiva que valoriza a formação do cidadão, e não uma abordagem baseada unicamente no conteúdo e que desconsidera aspectos sociais e tecnológicos, e que exige um maior grau de inserção de contextos, quando da produção do novo texto do saber. $\mathrm{O}$ professor P2 defende uma abordagem dinâmica do conteúdo, e relata que "[...] se tivesse algo ao qual daria maior importância, mesmo acreditando que tudo deve ser trabalhado de maneira 
homogênea, seria a parte teórica relacionada aos fatores que afetam a velocidade de uma reação, pois os cálculos são menos importantes que entender os resultados".

A busca por uma maior contextualização, uma abordagem matemática mais ampla (o professor P3 trabalha com meia vida das reações) ou a ênfase maior na interpretação das leis da natureza que nos cálculos de grandezas se relacionam a dimensão temporal, sobretudo ao tempo do professor (CÂMARA DOS SANTOS, 1997), e está associado a relação que os professores possuem com o saber Cinética Química.

\section{e) Como você encara os processos de recontextualização e repersonalização dos saberes no conteúdo de Cinética Química?}

A visão do professor P1 sobre os processos de recontextualização e repersonalização é bem direta. Esse professor afirma que trabalha com situações-problema, dando exemplos do cotidiano, com cuidado ao observar o meio social e escolar dos estudantes. Os professores P2 e P3 responderam com mais detalhes em relação a gestão desses processos, como podemos ver na transcrição de suas respostas:

"As aulas no ensino médio são bem corridas... Porém, sempre busco discutir com os alunos acontecimentos da atualidade que tenham envolvimento com o conteúdo que esteja sendo trabalhado, neste caso, cinética química... eu não chamaria de contextualização o que fiz com os alunos até então acerca desse conteúdo, porque contextualizar vai além de discutir algo, mesmo relacionado ao conteúdo..." (P2)

"Bem, na verdade eu trago exemplos do cotidiano. Ainda não tratei este conteúdo de forma contextualizada. Pretendo trazer elementos da cinética para discutir, por exemplo, o desperdício de alimentos nas grandes distribuidoras. Com certeza dará um ótimo debate. Contudo quando eu faço experimentos de eletroquímica e construo pilhas de laranjas, obtenho a diferença de potencial da pilha a partir de frutos maduros conservados e não conservados na geladeira. Os valores da diferença de potencial são bem diferentes por conta dos processos químicos diretamente associados à velocidade da reação de oxidação do fruto. Assim, retomo a cinética em outro contexto." (P3)

Tomando por base as respostas dessa e das outras perguntas, percebemos que o trabalho de repersonalização é mais desenvolvido pelo professor P3, talvez devido a sua formação na pós-graduação. O novo texto do saber se apresenta mais desenvolvido em relação aos tratamentos matemáticos e tecnológicos, como na abordagem do conceito de meia vida e interesse por processos industriais.

\section{CONSIDERAÇÕES FINAIS}

As transformações as quais o saber é submetido desde a academia, quando se apresenta na forma de saber científico, até as escolas, na manifestação do saber a ser ensinado e saber

ISSN 1982-4866. Revista Dynamis. FURB, Blumenau, v. 22, n. 2, p. 3-17, 2016 
ensinado, são bastante perceptíveis na abordagem da cinética química, com muitas modificações identificadas a partir da análise do trabalho externo de transposição didática.

Percebemos que o processo de transposição didática externa para o conteúdo de cinética química é rico em supressões, mais do que qualquer outra forma de modificação do saber. Contudo, foi possível observar também acréscimos e deformações, além da ocorrência de criações didáticas, principalmente sugestões de experimentos e informações históricas adicionais. Essas modificações são inevitáveis na transposição do saber, uma vez que a natureza e intencionalidade do saber é modificada, para que seja mais didático e se constitua como um objeto de ensino.

Qualquer menção a equação de Arrhenius foi suprimida nas obras destinadas ao Ensino Médio. Essa equação e suas aplicações também não são levadas em consideração pelos professores durante suas aulas, na construção do novo texto do saber, o que se caracterizou como uma supressão relevante e positiva, pois uma abordagem mais complexa da matemática pode criar obstáculos na aprendizagem dos conceitos e interpretações do saber.

$\mathrm{Na}$ análise da entrevista com os professores, foi possível observar como a relação do professor ao saber influencia a forma como ele vai ensinar o conteúdo, ou seja, na elaboração do novo texto do saber e na escolha das estratégias de ensino. O tempo que cada conceito fica em cena no jogo didático é associado a essa relação: se for um tópico no qual o professor tem maior conhecimento e prazer em ensinar, maior será o tempo destinado, mais exemplos surgirão, mais aplicações serão relatadas, mais discussões serão realizadas e o trabalho intramuros de sala de aula se constrói de forma diferente.

\section{REFERÊNCIAS}

ASTOLFI, J. et al.. Mots-clés de la didactique des sciences: repères, définitions, bibliographies. Bruxelles: De Boeck \& Larcier, 1997.

ALMOULOUD, S. A. As Transformações do Saber Científico ao Saber Ensinado: o caso do logaritmo. Educar em Revista, especial, p. 191-210, 2011.

BESSA DE MENEZES, M.; LINS, M.; BRITO MENEZES, A. P. A. A emergência de fenômenos didáticos em sala de aula - A negociação de uma sequência didática em álgebra inicial. In: IX ENCONTRO NACIONAL DE EDUCAÇÃO MATEMÁTICA, Belo Horizonte, 2010.

BROUSSEAU, G. Fundamentos e Métodos da Didática da Matemática. In: BRUN, J. (Org.). Didática das Matemáticas. Lisboa: Instituto Piaget, 1999.

BROUSSEAU, G. (1986) Fondements et méthodes de la didactique des mathématiques. Recherche en didactique des mathématiques, v.7, n.2, p. 33-115, 1986.

MENEZES, A. P. de A. B. Contrato Didático e Transposição Didática: Inter-relações entre os Fenômenos Didáticos na Iniciação à Álgebra na $6^{\mathrm{a}}$ série do Ensino Fundamental. $411 \mathrm{f}$. Tese (Doutorado em Educação) - Universidade Federal de Pernambuco, Recife, 2006.

CHASSOT, A. I.. Catalisando Transformações em Educação. Ijuí-RS: Editora da Unijuí, 1993.

CHEVAlLARD, Y. La Transposicion Didactique. Paris: La Pensee Sauvage, 1991. 
BATISTA FILHO, A. R. et al. Transposição Didática no Ensino de Ciências: Facetas de uma Escola do Campo de Parintins/AM. Areté - Revista Amazônica de Ensino de Ciências, v.5, n. 8, p. 71-82, 2012.

FRANZOLIN, F., TOLETINO-NETO, L. C. B. \& BIZZO, N. Generalizações que distanciam os conhecimentos dos livros didáticos das referências em Genética. Investigação em Ensino de Genética, v.9, n.2, 2014.

LIMA, J. F. L. et al. A contextualização no ensino de cinética química. Química Nova na Escola, n.11, p. 26-290, 2000.

MARTORANO, A. A. S. As concepções de ciência dos livros didáticos de química, dirigidos ao ensino médio, no tratamento da cinética química no período de 1929 a 2004. $226 \mathrm{f}$.

Dissertação (Mestrado em Ensino de Ciências) - Universidade de São Paulo, São Paulo, 2007.

MARTORANO, A. A. S. A transição progressiva dos modelos de ensino sobre cinética química a partir do desenvolvimento histórico do tema. $360 \mathrm{f}$. Tese (Doutorado em Ensino de Ciências) - Universidade de São Paulo, São Paulo, 2012.

MARTORANO, A. A. S.; CARMO, M. P.; MARCONDES, M. E. R..A História da Ciência no Ensino de Química: o ensino e aprendizagem do tema cinética química. História da Ciência e Ensino - Construindo Interfaces, v. 9, p. 19-35, 2014.

MELZER, E. E. M. Do saber sábio ao saber a ensinar: a transposição didática do conteúdo modelo atômico de livros de química (1921-2012). Universidade Federal do Paraná, 2012.

NEVES, K. C. R.; BARROS, R. M. Diferentes olhares acerca da transposição didática. Investigações em Ensino de Ciências, v.16, n.1, p. 103-115, 2011.

PINHO ALVES, J. Regras da transposição didática aplicada ao laboratório didático. Caderno Catarinense de Ensino de Física, v.17, n. 2, p. 174-188, 2000.

SANTOS, M. C. dos. O professor e o tempo. Tópicos Educacionais. v.15, n.1 e 2, p. 105-116, 1997.

SANTOS, W. L. P.; SCHNETZLER, R. P. Educação em Química: compromisso com a cidadania. Ijuí: Editora Unijuí, 2003.

SILVA, P. N.; SILVA, F. C. V.; SIMÕES NETO, J. E. A Transposição Didática do Conteúdo de Reações Orgânicas. Gôndola, v.10, n.2, p.35-48, 2015.

SILVA, P. N.; SILVA, F. C. V.; SIMÕES NETO, J. E. A Transposição Didática como recurso para análise do Saber intramuros da sala de aula do conteúdo Termoquímica. In: XVII ENCONTRO NACIONAL DE ENSINO DE QUÍMICA, Ouro Preto-MG, 2014.

SILVA, P. N. et al. A Análise da Transposição Didática para o Conteúdo de Reações Orgânicas: Primeiras Impressões. In: IX ENCONTRO NACIONAL EM PESQUISA EM EDUCAÇÃO EM CIÊNCIAS, Águas de Lindóia-SP, 2013. 